\title{
HYPERTENSIVE DISORDERS IN DIABETIC PREGNANCIES- EXPERIENCE FROM A TERTIARY CARE HOSPITAL IN KERALA
}

\author{
Coockoo Lal' ${ }^{1}$, Asha Gopi Nath²
}

${ }_{1}^{1}$ Senior Resident, Department of Obstetrics and Gynaecology, Government Medical College, Kottayam, Kerala, India.

${ }^{2}$ Associate Professor, Department of Obstetrics and Gynaecology, Government Medical College, Kottayam, Kerala, India.

\begin{abstract}
BACKGROUND
ABSTRACT

Hypertensive disorders of pregnancy complicate 5-10\% of all pregnancies. Pre-eclampsia and eclampsia are leading threats to safe motherhood in developing countries. Studies showing the association between hypertensive disorders of pregnancy and diabetes are generally based on data from western settings. The main objective of the present study is to find out as to whether the proportion of hypertensive disorders in diabetic pregnancies is more compered to euglycemic patents in a tertiary care hospital in Kerala.
\end{abstract}

\section{MATERIALS AND METHODS}

A prospective observational study was conducted among antenatal women diagnosed to have diabetes (GDM/overt) who received antepartum care at Govt. Medical College Kottayam. The controls were matched normoglycemic patients. Information was collected using questionnaires. BP was measured using standard methods with Korotkoff 1 for systolic BP and Korotkoff 5 for diastolic BP. BP more than 140/90 on two occasions six hours apart was taken as hypertension. For detecting diabetes, IADPSG values of fasting $92 \mathrm{mg} / \mathrm{dl}(>5.2 \mathrm{mmol} / \mathrm{l}), 1 \mathrm{hr} .150 \mathrm{mg} / \mathrm{dl} \mathrm{(>10.0} \mathrm{mmol/l)} \mathrm{and} 2 \mathrm{hrs} .153 \mathrm{mg} / \mathrm{dl}(8.5 \mathrm{mmol} / \mathrm{l})$ were taken.

\section{RESULTS}

Of the 241 patients, majority belong to the age group 21-30 (83\%). 56.5\% were primigravidas. Diabetic pregnant ladies are more prone to develop hypertensive disorders of pregnancy (21.4\%) as compared to nondiabetics (12.1\%). Of the diabetics, majority 94 (87.8\%) belongs to GDM group and $13(12.2 \%)$ were overt DM. Out of the $214(16.8 \%)$ developed hypertensive disorders of pregnancy. Among the diabetic patients those with overt DM are at a higher risk of developing hypertensive disorders (38.4\% with overt DM and $19.1 \%$ of GDM). In the GDM group, $11.7 \%$ developed gestational hypertension, $5.3 \%$ preeclampsia and $2.1 \%$ eclampsia. Among overt diabetics, 38\% developed preeclampsia. There were no cases of gestational hypertension or eclampsia among overt DM patients. $60 \%$ of diabetics who developed hypertension had poor glycaemic control which shows that glycaemic control had a strict relation with development of hypertension in diabetic patients.

\section{CONCLUSION}

There was increased incidence of hypertensive disorders of pregnancy in diabetic patients compared to nondiabetic controls in our setting also. Those with poor glycaemic control are at increased risk of developing hypertension.

\section{KEY WORDS}

Hypertensive Disorders of Pregnancy (HDP), Gestational Diabetes (GDM), Overt Diabetes (Overt DM)

HOW TO CITE THIS ARTICLE: Lal C, Nath AG. Hypertensive disorders in diabetic pregnancies- experience from a tertiary care hospital in Kerala. J. Evolution Med. Dent. Sci. 2019;8(09):565-568, DOI: 10.14260/jemds/2019/126

\section{BACKGROUND}

Hypertensive disorders complicate $5-10 \%$ of all pregnancies. ${ }^{1}$ They are classified as chronic hypertension, gestational hypertension, preeclampsia, eclampsia and chronic hypertension with superimposed preeclampsia. Gestational hypertension, preeclampsia and eclampsia are the mostcommon among HDP. It is responsible for $12-25 \%$ of cases of maternal mortality during pregnancy and pueperium. ${ }^{2}$ They are leading threats to safe motherhood in developing countries, where a woman in seven times more likely to develop these conditions. ${ }^{3}$

'Financial or Other Competing Interest': None.

Submission 06-01-2019, Peer Review 17-02-2019,

Acceptance 22-02-2019, Published 04-03-2019.

Corresponding Author:

Dr. Asha Gopi Nath,

Associate Professor,

Department of Obstetrics and Gynaecology,

Government Medical College,

Kottayam, Kerala, India.

E-mail: drgnathasha@gmail.com

DOI: $10.14260 /$ jemds/2019/126
Gestational diabetes is defined as carbohydrate intolerance with onset-or first recognition in pregnancy. The prevalence of GDM varied from 3.8 to $21 \%{ }^{8}$ in different parts of the country. The newer one step approach is based on a 75-g oral glucose tolerance test and was developed by the International Association of Diabetics in Pregnancy Study Group (IADPSG), which included ADA. GDM in diagnosed if fasting blood sugar values are $\geq 92 \mathrm{mg} / \mathrm{dl}, 1 \mathrm{hr} \geq 180 \mathrm{mg} / \mathrm{dl}$ and $2 \mathrm{hr} \geq 153 \mathrm{mg} / \mathrm{dl}$.

Compared with non-diabetics, women with diabetes are at considerably higher risk of $\mathrm{HDP}^{4}$. At least $20 \%$ of pregnant diabetic women will develop gestational hypertension or preeclampsia. ${ }^{5}$ Gestational diabetes also increases a woman's risk for $\mathrm{HDP}^{6,7}$ odds ratio [OR] 1.5 .

Prevalence of DM ranges from 2-22\% of all pregnancies. ${ }^{8}$ The number of pregnant women with pre-existing diabetes and difficulties associated with diagnosing preeclampsia in women with proteinuria prior to pregnancy are significant barriers to research in high risk population.

The presence of pre-existing and gestational diabetes increases the risk of HDP leading to higher maternal and fetal morbidity. It poses a management challenge to the treating 
obstetrician. So diabetic women must be closely followed up prior to conception and throughout gestation to minimize the risk of developing HDP and its associated complications. Since Indian studies are less the main objective of the present study is to find out the proportion of hypertensive disorders in pregnant ladies with diabetes compared to euglycemic controls.

\section{MATERIALS AND METHODS}

It was a prospective observational study conducted on antenatal women who were diagnosed to have diabetes mellitus (overt/GDM) and received antepartum, intrapartum and postpartum care at GMC Kottayam for a period of six months. Matched normoglycemic patients were taken as controls. After getting ethical committee clearance and consent from patients, and applying inclusion criteria and exclusion criteria antenatal women were taken up for the study. History was taken and clinical examination done and patients with diabetes were followed up during antenatal period for the development of hypertensive disorders. Information was collected using questionnaires'. BP was taken using standard methods with Korotkoff 1 for systolic BP and Korotkoff 5 for diastolic BP. BP more than 140/90 on two occasions six hours apart was taken as hypertension. For detecting diabetes IADPSG values of fasting $92 \mathrm{mg} / \mathrm{dl}(>5.2$ mmol/l), $1 \mathrm{hr} .150 \mathrm{mg} / \mathrm{dl}$ (>10.0 mmol/l) and $2 \mathrm{hrs} .153$ $\mathrm{mg} / \mathrm{dl}(8.5 \mathrm{mmol} / \mathrm{l})$ were taken. Those having multiple pregnancy, chronic hypertension, renal disease, collagen vascular disease, hyperthyroidism were excluded from the study.

\section{Sample Size was calculated with the Formula-}

$$
\mathrm{n}=\frac{\left(\mathrm{Z}_{1-\alpha / 2}+\mathrm{Z}_{1-\beta}\right)^{2}\left(\mathrm{P}_{1}\left(1-\mathrm{P}_{1}\right)+\mathrm{P}_{2}\left(1-\mathrm{P}_{2}\right)\right]}{\left(\mathrm{P}_{1}-\mathrm{P}_{2}\right)^{2}}
$$

$\mathrm{P}_{1}=$ Proportion with hypertension among AN mothers with no GDM (control)

$\mathrm{P}_{2}=$ Proportion with hypertension among AN mothers with GDM (study group)

Based on a pilot study $\mathrm{P}_{1}=.12$ and $\mathrm{P}_{2}=.28$ and $\mathrm{n}=97$ per group. Anticipating $10 \%$ dropout rate final sample size is 107 per group.

Data was entered in excel spread sheet and statistical analysis is with SPSS software. Qualitative variables were expressed in percentages, quantitative variables will be expressed in mean (SD). Association was found out using chisquare test and strength of association was assessed using odd's ratio.

\section{RESULTS}

In the study majority $84 \%$ belongs to age group $21-30$ years Primigravida constituted 56.5\%.

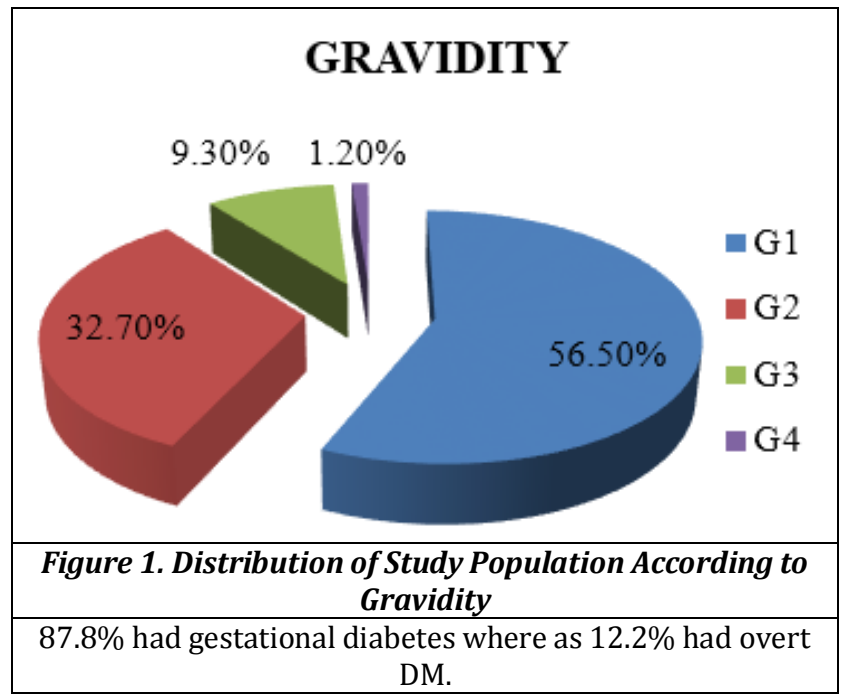

\section{DIABETES MELLITUS}

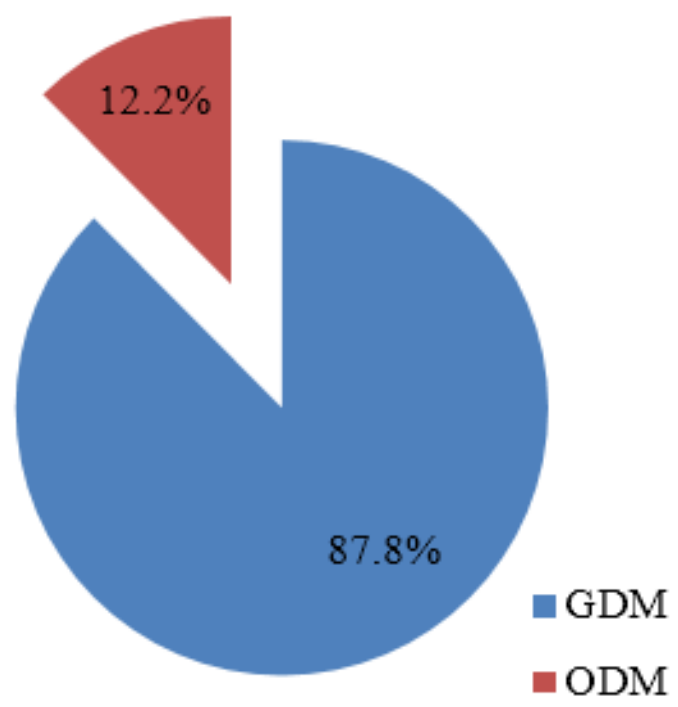

Figure 2. Distribution of Types of Diabetes Militates

$16.8 \%$ in study group developed hypertensive disorders of pregnancy. ( $44 \%$ gestational hypertension, $44 \%$ preeclampsia and $12 \%$ developed eclampsia).

\begin{tabular}{|c|c|c|}
\hline & Number & Percentages \\
\hline $\begin{array}{c}\text { Hypertensive Disorders of } \\
\text { Pregnancy }\end{array}$ & $\mathbf{3 6}$ & $\mathbf{1 0 0 \%}$ \\
\hline Gestational Hypertension & 16 & $44 \%$ \\
\hline Preeclampsia & 16 & $44 \%$ \\
\hline Eclampsia & 4 & $12 \%$ \\
\hline $\begin{array}{c}\text { Table 1. Distribution of Various Hypertensive Disorders of } \\
\text { Pregnancy }\end{array}$ \\
\hline
\end{tabular}

Among the diabetic patients $38.4 \%$ of overt diabetes and $19.1 \%$ of gestational diabetes developed hypertensive disorders. 


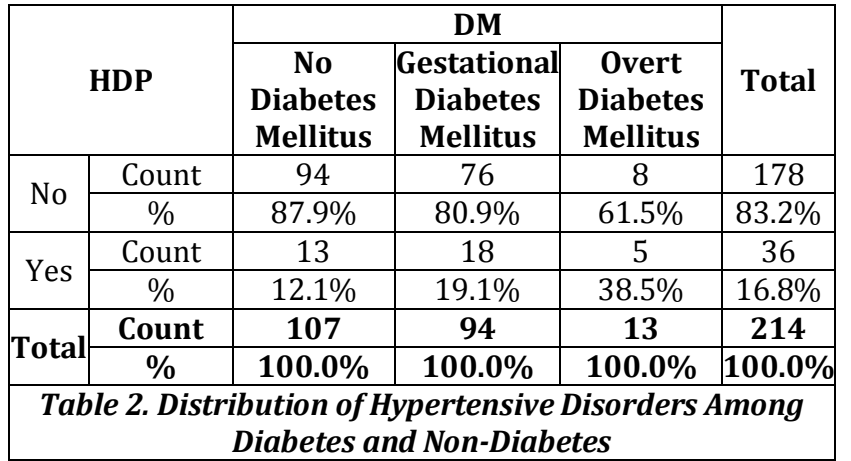

There was a statistically significant association between hypertensive disorders of pregnancy and presence of diabetes mellitus with a Chi-square value of 6.38 at $p$ value of $<0.05$.

\begin{tabular}{|c|c|c|c|c|c|}
\hline \multirow{2}{*}{\multicolumn{2}{|c|}{$\begin{array}{l}\text { Hypertensive } \\
\text { Disorders of } \\
\text { Pregnancy }\end{array}$}} & \multicolumn{3}{|c|}{ DM } & \multirow[b]{2}{*}{ Total } \\
\hline & & \multirow{2}{*}{\begin{tabular}{|c|}
$\begin{array}{c}\text { No } \\
\text { Diabetes } \\
\text { Mellitus }\end{array}$ \\
94 \\
\end{tabular}} & \multirow{2}{*}{\begin{tabular}{|c|}
$\begin{array}{c}\text { Gestational } \\
\text { Diabetes } \\
\text { Mellitus }\end{array}$ \\
76 \\
\end{tabular}} & \multirow{2}{*}{$\begin{array}{c}\begin{array}{c}\text { Overt } \\
\text { Diabetes } \\
\text { Mellitus }\end{array} \\
8 \\
\end{array}$} & \\
\hline Nil & Count & & & & 178 \\
\hline & & $87.9 \%$ & $80.9 \%$ & $61.5 \%$ & $83.2 \%$ \\
\hline \multirow{2}{*}{\begin{tabular}{|c|} 
Gestational \\
Hyper- \\
tension
\end{tabular}} & Count & 5 & 11 & 0 & 16 \\
\hline & $\%$ & $4.7 \%$ & $11.7 \%$ & $0.0 \%$ & $7.5 \%$ \\
\hline \multirow{2}{*}{\begin{tabular}{|c|} 
Pre- \\
Eclampsia
\end{tabular}} & Cour & 6 & 5 & 5 & 16 \\
\hline & $\%$ & $5.6 \%$ & $5.3 \%$ & $38.5 \%$ & $7.5 \%$ \\
\hline \multirow{2}{*}{ Eclampsia } & Coun & 2 & 2 & 0 & 4 \\
\hline & $\%$ & $1.9 \%$ & $2.1 \%$ & $0.0 \%$ & $1.9 \%$ \\
\hline \multirow{2}{*}{ Total } & Count & 107 & 94 & 13 & 214 \\
\hline & $\%$ & $100.0 \%$ & $100.0 \%$ & \multicolumn{2}{|c|}{\begin{tabular}{|l|l|}
$100.0 \%$ & $100.0 \%$ \\
\end{tabular}} \\
\hline
\end{tabular}

There was an increased proportion of HDP among the patient taking insulin compared to those on MNT \& OHA. $\chi^{2}-$ 43.42, p- 0.03. This is probably reflecting the fact that patients taking insulin were having increased severely of diabetics.

\begin{tabular}{|c|c|c|c|c|c|c|}
\hline & \multicolumn{3}{|c|}{ FBS } & \multirow{2}{*}{ Total } \\
\hline & & & $<92 \mathrm{mg} / \mathrm{dL}$ & 93-105 & $>105$ & \\
\hline \multirow{4}{*}{ HDP } & \multirow[b]{2}{*}{ No } & Count & 60 & 13 & 11 & 84 \\
\hline & & $\begin{array}{l}\text { \% Within } \\
\text { FBS }\end{array}$ & $92.3 \%$ & $65 \%$ & $50 \%$ & $78.5 \%$ \\
\hline & \multirow[b]{2}{*}{ Yes } & Count & 5 & 7 & 11 & 23 \\
\hline & & $\begin{array}{l}\text { \% Within } \\
\text { FBS }\end{array}$ & $7.7 \%$ & $35 \%$ & $50 \%$ & $21.5 \%$ \\
\hline \multirow{2}{*}{\multicolumn{2}{|c|}{ Total }} & Count & 65 & 20 & 22 & 107 \\
\hline & & $\begin{array}{l}\text { \% Within } \\
\text { FBS }\end{array}$ & $100.0 \%$ & $100.0 \%$ & $100.0 \%$ & $100.0 \%$ \\
\hline \multicolumn{7}{|c|}{$\begin{array}{c}\text { Table 4. Association Between Glycaemic Control and } \\
\text { Presence Of HDP }\end{array}$} \\
\hline
\end{tabular}

\section{DISCUSSION}

In our study majority $84 \%$ belonged to age group $21-30$ years which is similar to study by Prakash et al. ${ }^{9} 56.5 \%$ in our study were primigravidas whereas majority were second gravida in their study.

In the present study, there was a significantly higher proportion of hypertensive disorders of pregnancy (HDP) in the diabetes group compared to those without diabetes. $38 \%$ of overt diabetes and $19 \%$ of those with gestational diabetes developed gestational hypertension and/or preeclampsia, with the most at-risk patients being those with high body mass index and poor glycemic control. In a Finnish cohort, preeclampsia was 5 times more frequent and Gestational hypertension was twice as frequent in women with Type 1 DM without nephropathy compared with nondiabetic controls. 10 Glycemic control, particularly during the first half of pregnancy, is a strong predictor of hypertensive disorders in women with both overt and gestational diabetes mellitus. The findings in the study are in accordance with many of the previous studies. Tobias et al ${ }^{11}$ in a large prospective cohort study investigated the association between GDM and subsequent risk of hypertension after the index pregnancy among 25, 305 women who reported at least one singleton pregnancy between 1991 and 2007 in the Nurses' Health Study II. During 16 years of follow-up, GDM developed in 1, 414 women $(5.6 \%)$ and hypertension developed in $3,138$. The women with a history of GDM had a $26 \%$ increased risk of developing hypertension compared with those without a history of GDM. These results indicate that women with GDM are at a significant increased risk of developing hypertension.

$16.8 \%$ in our study group developed hypertensive disorders of pregnancy. In study by Prakash et al where they included gestational diabetic patients only 31\% had gestational HT and 9\% had chronic hypertension. The lesser percentage of hypertension in our study may be related to better glycaemic control.

In our study $44 \%$ developed gestational HT, 44\% developed preeclampsia and $12 \%$ developed eclampsia. In a study by Weissberger et al ${ }^{7}$ preeclampsia was diagnosed in $15-20 \%$ cases with type 1 diabetes. Preeclampsia was $5.3 \%$ in gestational DM and 38.5\% in overt DM in our study showing that overt DM has a definitely higher risk of developing HDP. But in our study the incidence of eclampsia was $2.1 \%$ in gestational DM and none in overt DM. There was no statistically significant difference about developing HDP in overt and GDM in our study with $p>0.05$ (0.11). It may be due to less number of patients in overt DM group. In a populationbased study of deliveries in Washington states, pre-existing DM was a risk factor for both early onset (Diagnosis before 34 weeks' gestation) hazard ratio (HR): 1.87, 95\% confidence interval CI: 60-2.81 and late onset preeclampsia (HR: 2.46, 95\%, CI: 2.52-2.61).

Study by Carisis et al 12 also found increased risk of preeclampsia in woman with underlying pre-gestational DM with rates of preeclampsia approximately $25 \%$ and $20 \%$ in diabetic and non-diabetic patients respectively.

In a study from Riode janeiro by Luciana Lourenco et al ${ }^{13}$ which studied HDP in woman with GDM they found $19.5 \%$ case of HDP of which $9.2 \%$ had GHT \& $10.3 \%$ had preeclampsia.

In a large nationally representative cross-sectional study by Sutapa Agarwal et $\mathrm{al}^{14}$ the prevalence of symptom suggestive of preeclampsia and eclampsia in woman with diabetes was $1.8 \%$ ( $\mathrm{n}=207 ; 95 \%$ CI: 1.5 to $2.0 ; \mathrm{p}<0.0001)$ and $2.1 \%$. ( $\mathrm{n}=85 ; 95 \% \mathrm{CI}: 1.8$ to $2.3, \mathrm{p}<0.0001$ ) respectively. Which shows HDP is strongly associated with the risk of diabetes in a large nationally representative sample of Indian woman.

A retrospective case control study of 97 woman with new onset hypertension in late pregnancy and 77 normotensive control gravidas demonstrate that after adjustment of BMI 
and base line systolic and diastolic BP the post GCT value at 24-28 weeks was significantly higher among those developing hypertension. ${ }^{15}$

In our study there was an increased proportion of HDP in patient with uncontrolled glycaemic status. Those with FBS $>105 \mathrm{mg} / \mathrm{dl}$ HDP was $50 \%$, 93-105 mg/dl was $35 \%$ and $<92$ $\mathrm{mg} / \mathrm{dl}$ was $7.7 \%$ respectively. The Toronto Tri hospital project Cohort study 16 also showed a similar association, but postprandial value showed significance especially 2-hour values. Among those with values $<5.6 \mathrm{mmol} / \mathrm{L} 3.3 \%$ had preeclampsia, with rates rising to $4.7,6.5$ and $6.4 \%$ among those in the 5.6-6.4, 6.5-7.3, and $>7.3 \mathrm{mmol}$ strata.

A secondary analysis of the Calcium for Preeclampsia Prevention Multicenrtic Calcium, Prophylaxis Trial also conformed the association between glucose tolerance and subsequent gestational hypertension. ${ }^{17}$

\section{CONCLUSION}

It was evident from the present study that there was a significant increase in the proportion of hypertensive disorders of pregnancy in patients with diabetes. Regular antenatal checkups and strict glycaemic control among pregnant females with diabetes is recommended to decrease the risk of hypertensive disorders of pregnancy. All diabetic women contemplating pregnancy need to be counselled regarding the importance of prevention during the preconception period and require close medical attention during gestation and postpartum period.

\section{ACKNOWLEDGEMENT}

We are extremely thankful to Prof. Dr. C. P. Vijayan, Professor and HOD, Department of Obstetrics and Gynaecology, for the valuable suggestions and guidance. We also express our sincere thanks to all the patients who participated in our study.

\section{REFERENCES}

[1] Sullivan SD, Umans JG, Ratner R. Hypertension complicating diabetic pregnancies: pathophysiology, management and controversies. J Clin Hypertens (Greenwich) 2011;13(4):275-84.

[2] World health organization collaboration the world health report: make every mother and child count. Department of reproductive health and research, WHO, $2005 . \quad$ http://www. who.int/whr/2005/en/indix.html (Accessed on Aug 2015).

[3] Maternal mortality in 2005: estimates developed by WHO, UNICEF, UNIFPA and The World Bank, Gineva: World Health Organisation, 2007.

http://www.who.imty. whosis/ mme_2005.pdf.
[4] Garner PR, D'Alton ME, Dudley DK, et al. Preeclampsia in diabetic pregnancies. Am J Obstet Gynecol 1990;163(2):505-8.

[5] Bond MJ, Umans JG. Microvascular complications and the diabetic pregnancy. Curr Diab Rep 2006;6(4):2916.

[6] Bryson CL, Ioannou GN, Rulyak SJ, et al. Association between gestational diabetes and pregnancy-induced hypertension. Am J Epidemiol 2003;158(12):1148-53.

[7] Weissgerber TL, Mudd LM. Pre-eclampsia and diabetes. Curr Diab Rep 2015;15(3):9.

[8] Djomhou M, Sobngwi E, Noubiap JJN, et al. Maternal hyperglycemia during labor and related immediate post-partum maternal and perinatal outcomes at the Yaoundé Central Hospital, Cameroon. Journal of Health, Population and nutrition 2016;35:28.

[9] Prakash TG, Das AK, Habeebullah S, et al. Maternal and neonatal outcome in mothers with gestational diabetes mellitus. Indian $\mathrm{J}$ Endocrinol Metab 2017;21(6):854-8.

[10] Conde-Agudelo A, Belizan JM. Risk factors of preeclampsia in a large cohort of Latin American and Caribbean women. BJOG 2000;107(1):75-83.

[11] Tobias DK, Hu FB, Forman JP, et al. Increased risk of hypertension after gestational diabetes mellitus: findings from a large prospective cohort study. Diabetic Care J 2011;34(7):1582-4.

[12] Caritis S, Sibai B, Hauth J, et al. Low dose aspirin to prevent preeclampsia in women at high risk. National Institute of Child Health and Human Development Network of Maternal-Fetal Medicine Units. N Engl J Med 1998;338(11):701-5.

[13] Dos Santos da Silva LLG, Saunders C, Campos ABF, et al. Hypertensive disorders of pregnancy in women with gestational diabetes mellitus from Rio de Janeiro, Brazil. Pregnancy Hypertension 2017;10:196-201.

[14] Agrawal S, Fledderjohann J. Hypertensive disorders of pregnancy and risk of diabetes in Indian women: a cross sectional study. BMJ Open 2016;6(8):e011000.

[15] Solomon CG, Graves SW, Greene MF, et al. Glucose intolerance as a predictor of hypertension in pregnancy. Hypertension 1994;23(6 Pt 1):717-21.

[16] Barden A, Singh R, Walters BN, et al. Factors pre disposing pre-eclampsia in women with gestational diabetes. J Hypertension 2004;22(12):2371-8.

[17] Joffe GM, Esterlitz JR, Levine RJ, et al. The relationship between abnormal glucose balance and hypertensive disorders of pregnancy in healthy nulliparous women. Calcium for preeclampsia prevention (CPEP) Study Group. Am J Obstet \& Gynecol 1998;179(4):1032-7. 